\title{
Development of seed analyses by means of various matrix solutions and the MALDI- TOF MS technique
}

\author{
${ }^{1}$ Csilla Bojté $-{ }^{2}$ Csaba Lovász $-{ }^{3}$ Eszter Timár $-{ }^{4}$ László Lajkó $-{ }^{5}$ János Nagy $-{ }^{1}$ Nikoletta Edit Nagy - \\ ${ }^{1}$ Karina Bodnár $-{ }^{6}$ Laura Czerődiné Kempf $-{ }^{7}$ Brigitta Horváth $-{ }^{2}$ Adrienn Micsinai $-{ }^{8}$ Szilárd Tóth \\ ${ }^{1}$ Kerpely Kálmán Plant Production and Horticultural Sciences Doctoral School, 4032 Debrecen, Böszörményi út 138. \\ ${ }^{2}$ WESSLING Hungary Ltd, 1045 Budapest, Anonymus u. 6. \\ ${ }^{3}$ NÉBIH Central Seed Analysis Laboratory, 1024 Budapest, Kis Rókus u. 15/a. \\ ${ }^{4}$ PHYTOPATENT Ltd., 1012 Budapest, Mátray u. 10. 2.em/3. \\ ${ }^{5}$ University of Debrecen, Faculty of Agricultural and Food Sciences and Environmental Management, 4032 Debrecen, Böszörményi út 138. \\ ${ }^{6}$ Szent István University, 2100 Gödöllö, Páter Károly utca 1. \\ ${ }^{7}$ Livestock Farming Sciences Doctoral School, 4032 Debrecen, Böszörményi út 138. \\ ${ }^{8}$ Fleischmann Rudolf Research Institute, 3356 Kompolt, Fleischmann u. 4. \\ csillabojte1990@gmail.com
}

\section{SUMMARY}

The earth's population is growing steadily, currently accounting for about 7.3 billion people. Population growth causes food demand to rise, approximately 36 million people die each year due to starvation or related diseases. One solution to this problem is the continuous examination and development of the agricultural economy. In this study, matrix-assisted laser desorption/ionization time-of-flight mass spectrometer (MALDI -TOF MS) were used to analyse of sunflower, soybean and hemp. In order to analyse the protein of maize, this method has already been applied. However, for sunflower, soy and hemp, it is necessary to develop a sample preparation method. Choosing the optimal matrix solution for ionization the traget molecule is an essential part of developing the method. Our aim is to compare two different matrix solutions ( $\alpha$-HCCA, SA matrix), based on the properties (intensity, noise ratio, value of spectra) of the spectra.

Keywords: seed analyses, MALDI-TOF, protein profiling, biomarker proteins

\section{INTRODUCTION}

One of the most important attributes of seed quality is the value represented by the variety since the seed possesses all genetic abilities of the breed to be expected to unfold in the developing plant populations. Preservation of the variety value is therefore a prerequisite for the realization of the genetic potential inherent in the variety (hybrid) which requires testing abilities so that the value can be assessed before sowing.

It is necessary to develop a new alternative test method that can be used in the process of seed certification. The collaboration with the Seed Testing Laboratory of the National Food Chain Safety Office was initiated when the fact was demonstrated that pathological fungal infections affect the results of internationally accepted and used gel electrophoresis tests carried out via isoelectric focusing (International Seed Testing Association (ISTA), 2017). The developed new MALDI-TOF MS device has been designed to carry out complementary examinations. Mass Spectroscopy is an effective structural research method that, when applied, is used to transfer the analysed molecules to gas phase, ionize and accelerate them by means of a high-voltage electrical field. The accelerated ions are separated by mass and charge by magnetic, electrostatic, or radiofrequency spaces and their weight is determined. The size and molecular weight of the analysed molecule is one of the most important structural information provided by mass spectrometry. In terms of the mass spectrometry of macromolecules, the key issue is ionization. One of the solutions to the analysis of biologically active molecules - proteins, enzymes - might be the application of the MALDI ionization technology. Recently, the MALDI-TOF MS technique became a preferred method for the quantitative analysis of biomolecules (oligonucleotides, proteins, glycoproteins, etc.) originating from different types of samples (Mirgorodskaya et al., 2000; Hensel et al., 1997; Gutierrez et al., 2005).

Due to its higher sensitivity, MALDI-TOF MS technology more securely separates potential fungal contamination and genetic cleanness. Thus, the highvalue seed items can be saved from exclusion due to fungal infections. In the case of maize, this method has already been applied, but for sunflower, soy and hemp, it is necessary to develop a sample preparation method. Choosing the optimal matrix solution for ionization, the target molecule is an essential part of developing method. Our aim is to compare two different matrix solutions based on properties (intensity, noise ratio, value of spectra) of the spectra. In the present study, the fitness-for-purpose of two MALDI-TOF MS matrices, $\alpha$-cyano-4-hydroxy cinnamic acid ( $\alpha$-HCCA), and 3,5dimethoxy-4-hydroxy cinnamic acid (sinapinic acid or SA) were analysed.

\section{MATERIAL AND METHODS}

A soybean, sunflower and hemp sample were analysed by MALDI-TOF MS technique at the premises of WESSLING Hungary Ltd, Budapest, Hungary. During the examination, the sample preparation of the three seeds is different. Two different 
matrix solution and three different sample preparation methods were used for the best exploration of proteins of seeds. The different fat content and structure of the seeds made it necessary to modify of the sample preparations and test of matrix solutions.

\section{Preparation of the sample holder}

Sample holder plates were prepared for measurement and then soaked in $70 \%$ ethanol for 5 to 10 minutes, then rinsed with warm running water to remove residues of extracts. Subsequently, it was rubbed with a suspension of fine aluminium oxide and the plates were dried using paper towels. The plates were next soaked in methanol for 5 to 10 minutes, then the residue of the methanol was left to evaporate in a laminar box. The plates were soaked in 2-propanol for 30 seconds and then rubbed with a lint-free cloth. After drying in a laminar box, $50 \mu \mathrm{l}$ of $80 \%$ trifluoroacetic acid solution was pipetted into the middle of the plates, thoroughly rubbed with a cotton swab and the residue of trifluoroacetic acid residue was washed with deionized water. The dried plates were rubbed with a small amount of graphite powder, and the residue of the graphite powder was removed by a fine brush. The prepared sample plates were stored in petri dishes until the beginning of the examinations.

\section{Sample preparation methods of seeds \\ Extraction of sunflower seeds by 1-propanol buffer}

The husked and individually ground sunflower seeds were placed into $2 \mathrm{ml}$ Eppendorf centrifuge tubes. As a next step, $500 \mu \mathrm{l}$ of 1-propanol extraction agent was pipetted into the centrifuge tubes. To prepare the extraction solution, $1 \mathrm{ml}$ of acetic acid was used with 1 $\mathrm{g}$ of dithiothreitol, $50 \mathrm{ml}$ of 1-propanol and $50 \mathrm{ml}$ of deionized water. The Eppendorf tubes were thoroughly mixed with vortex and placed in an ultrasonic bath for 30 minutes. After the extraction was completed, the samples were centrifuged ( 3 minutes at $14500 \mathrm{rpm}$ ) and $50 \mu \mathrm{l}$ of the supernatant was pipetted into a clean $1.5 \mathrm{ml}$ Eppendorf tube. Following this, $50 \mu \mathrm{l}$ trifluoroacetic acid solution and $25 \mu$ l acetonitrile were pipetted into the Eppendorf tubes and the extract was mixed thoroughly by vortexing and centrifuging $(3 \mathrm{~min}$ at $14500 \mathrm{rpm}$ ). Finally, $1-1 \mu \mathrm{l}$ of the extract was pipetted onto the prepared sample MALDI-TOF plate in four parallel spots per sample.

Extraction of soybean seeds by $60 \mathrm{v} / \mathrm{v} \%$ ethanol buffer

The intact soybean seeds were placed individually into a $2 \mathrm{ml}$ Eppendorf centrifuge tubes. For the solution $40 \mathrm{ml}$ of deionized water and $60 \mathrm{ml}$ of absolute ethanol was used. Before sampling, the extract was mixed thoroughly with the vortex and centrifuged $(3 \mathrm{~min}$ at $14100 \mathrm{rpm})$. Thereafter, 1-1 $\mu$ l of the extract was dropped onto the prepared MALDI-TOF sample plate in four parallel spots per sample.

Extraction of hemp seeds by $70 \mathrm{v} / \mathrm{v} \%$ formic acid buffer

The intact hemp grains were placed individually into $2 \mathrm{ml}$ Eppendorf centrifuge tubes. To prepare the solutions $70 \mathrm{ml}$ of formic acid and $30 \mathrm{ml}$ of Milli Q distilled water was used. The extract was mixed with Vortex, then $500 \mu \mathrm{l}$ of ACN was added which terminated the reaction. This is necessary to prevent the proteins from decomposition. Before sampling, the extract was mixed thoroughly with the vortex and centrifuged ( $3 \mathrm{~min}$ at $14100 \mathrm{rpm}$ ) again. Thereafter, 1$1 \mu \mathrm{l}$ of the extract was dropped onto the prepared sample plate in four parallel spots per sample.

\section{Matrix solution}

In this study, the fitness-for-purpose of two MALDI-TOF MS matrices, $\alpha$-cyano-4-hydroxy cinnamic acid ( $\alpha$-HCCA matrix, ultra pure), and 3,5dimethoxy-4-hydroxy cinnamic acid (sinapic acid or SA matrix; ultra pure) was assessed. The MALDI-TOF plates containing the dried sample solutions were spotted by pipetting $1 \mu \mathrm{l}$ of $\alpha$-HCCA or $1 \mu \mathrm{l}$ of SA solution and the solvent was let to evaporate until dryness in a laminar box.

Figure 1: Structural formula of sinapic acid (SA)<smiles>COc1cc(/C=C/C(=O)O)cc(OC)c1O</smiles>

[http://thermofisher.com, 2016]

Figure 2: Structural formula of $\boldsymbol{\alpha}$-cyano-4-hydroxy cinnamic acid (HCCA)<smiles>N#C/C(=C\c1ccc(O)cc1)C(=O)O</smiles>

[http://thermofisher.com, 2016]

SA matrix solution $(25 \mathrm{mg} / \mathrm{ml}$ concentration): The SA matrix solution according to the study published by Dieckmann et al. (2008) was prepared by dissolving crystalline sinapic acid (Figure 1) in the 1:1 solution of deionized water containing $0.6 \%$ trifluoroacetic acid and acetonitrile for the required end concentration of 25 $\mathrm{mg} / \mathrm{ml}$, and aiding the process by intensive vortexing until all crystals were dissolved. The matrix solution was always freshly prepared on the day of use, and stored at $4^{\circ} \mathrm{C}$ protected from light.

$\alpha$-HCCA matrix solution $(10 \mathrm{mg} / \mathrm{ml}$ concentration): $\alpha$-HCCA matrix solution according to the study published by Signor and Erba (2013) was prepared by dissolving crystalline $\alpha$-HCCA (Figure 2 ) in a solution of deionized water containing $5 \%$ formic acid and 
acetonitrile in a ratio of $7: 3$ to reach the required concentration of $10 \mathrm{mg} / \mathrm{ml}$ for the $\alpha-\mathrm{HCCA}$, and aiding the process by intensive vortexing until all crystals were dissolved. The matrix solution was always freshly prepared on the day of use, and stored at $4^{\circ} \mathrm{C}$ protected from light.

\section{Measurement parameters of MALDI-TOF MS}

The general control software (flexControl - Bruker Daltonik) of the MALDI-TOF MS device lets the parameters of the analysis to be controlled: energy of the laser, the voltage required to accelerate the ions, the movement pattern of the sample plate and the analysed mass number range. Additionally, this software performs the calibration of the mass number scale of the device, that is, determining the function between the time-of-flight values and ion-mass number. For this reason, a known bacterial strain (Escherichia coli DH5) was used as a calibration standard. The prepared sample plate was put into the ion source via an air-lock system. Examination of the sample in the current position could be monitored through a low resolution digital camera.

After checking the vacuum, the laser was set to the calibration position and in automatic spectrum recording mode - the average mass spectrum of the calibration standard was prepared in the mass number range of 2000 to $25,000 \mathrm{amu}$ (atomic mass unit), preferably averaging 200 to 500 spectrums. Following noise reduction (smoothing) and baseline correction, calibration was performed (based on the reference mass numbers adjustments were made to the mass number function). The deviation of the reference mass numbers was checked and the calibration was accepted only if the deviation was less than $300 \mathrm{ppm}$ for each mass number. The mass spectrum of the DH5 mass spectrum used for calibration (Escherichia coli) contained a relatively high number of peaks therefore a sufficient number of ions could be found easily to cover the mass range (2000-25,000 amu) (Lovász, 2014). It was advisable to calibrate the MALDI-TOF device by standard measurement of reference bacteria before each set of samples.

\section{Evaluation of obtained MALDI-TOF MS spectra}

For the analysis of the mass spectra profiles, FlexAnalysis (Bruker Daltonik) software was used. With this software the individual mass spectra created from the samples could be viewed and the appropriate mathematical operations (noise reduction, baseline correction) with the developed and optimised method file.

\section{RESULTS AND DISCUSSION}

The $\alpha$-HCCA matrix is suitable for the separation of small molecular weight proteins while high molecular weight proteins can be separated by means of the SA matrix. Therefore, it is possible to isolate more than one protein from the same sample (Figure 3, 4, 5).

The use of the SA matrix increased intensivity by means of which the composition and the contamination levels of each sample can be more accurately determined. These data supply important information for the further development of analytical methods of plant seed materials.

Figure 3: The view of hemp spectrums was performed with HCCA and SA matrix solutions, extractions of proteins was done with $\mathbf{7 0 \%}$ formic acid extraction

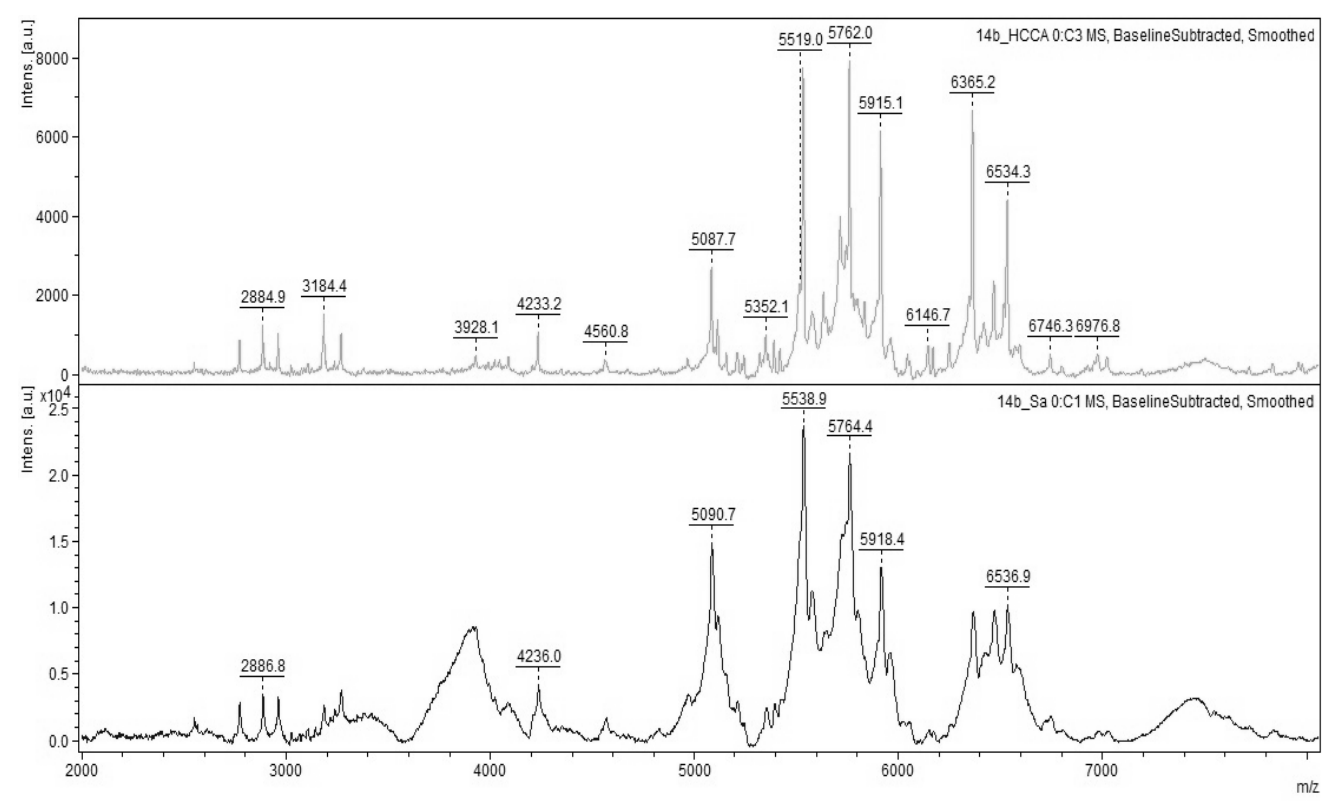


Figure 4: The view of soybean spectrums was performed with HCCA and SA matrix solutions, extractions of proteins was done with $60 \%$ ethanol extraction

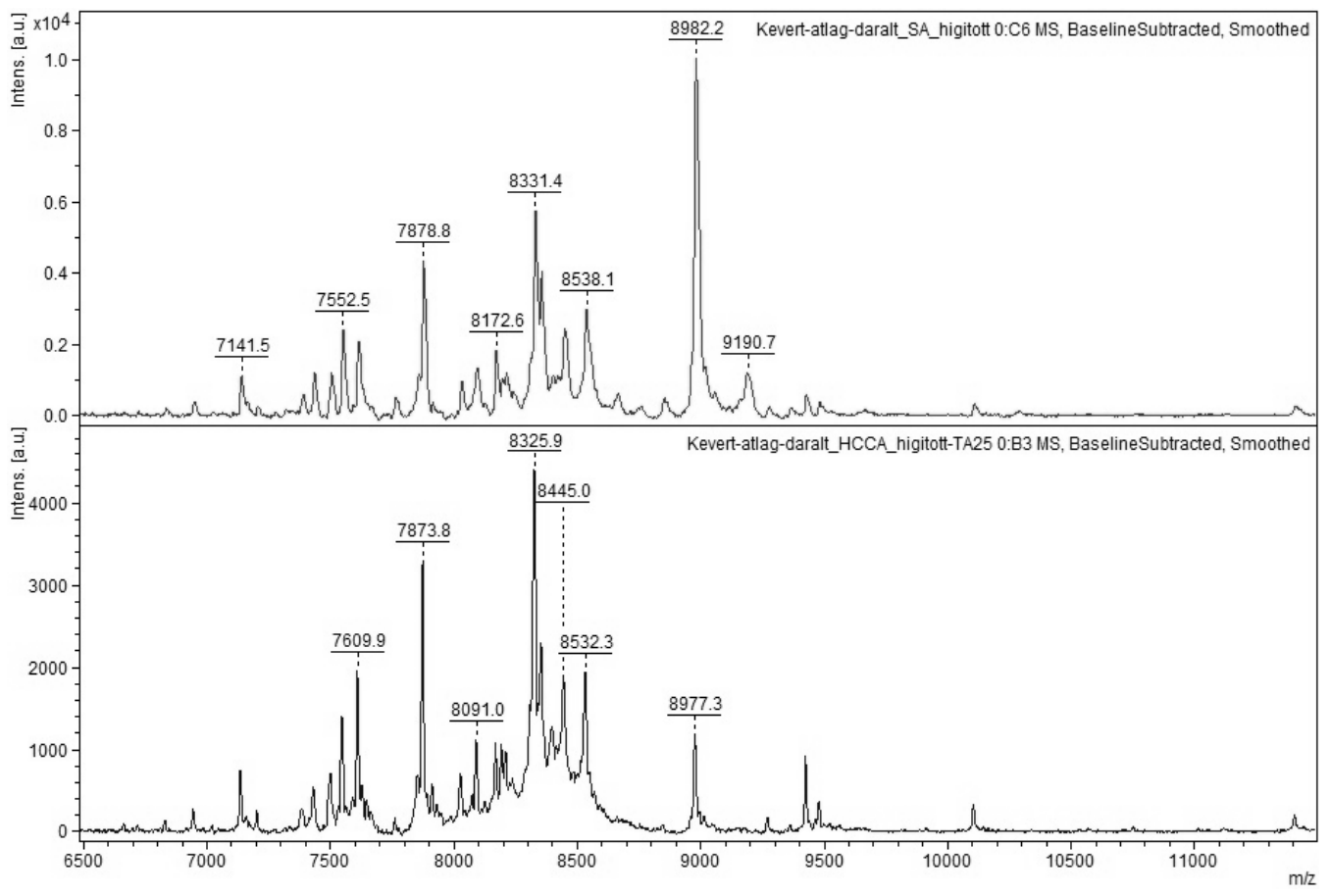

Figure 5: The view of husked sunflower kernels was performed with HCCA and SA matrix solutions, extractions of proteins was done with 1-propanol extraction

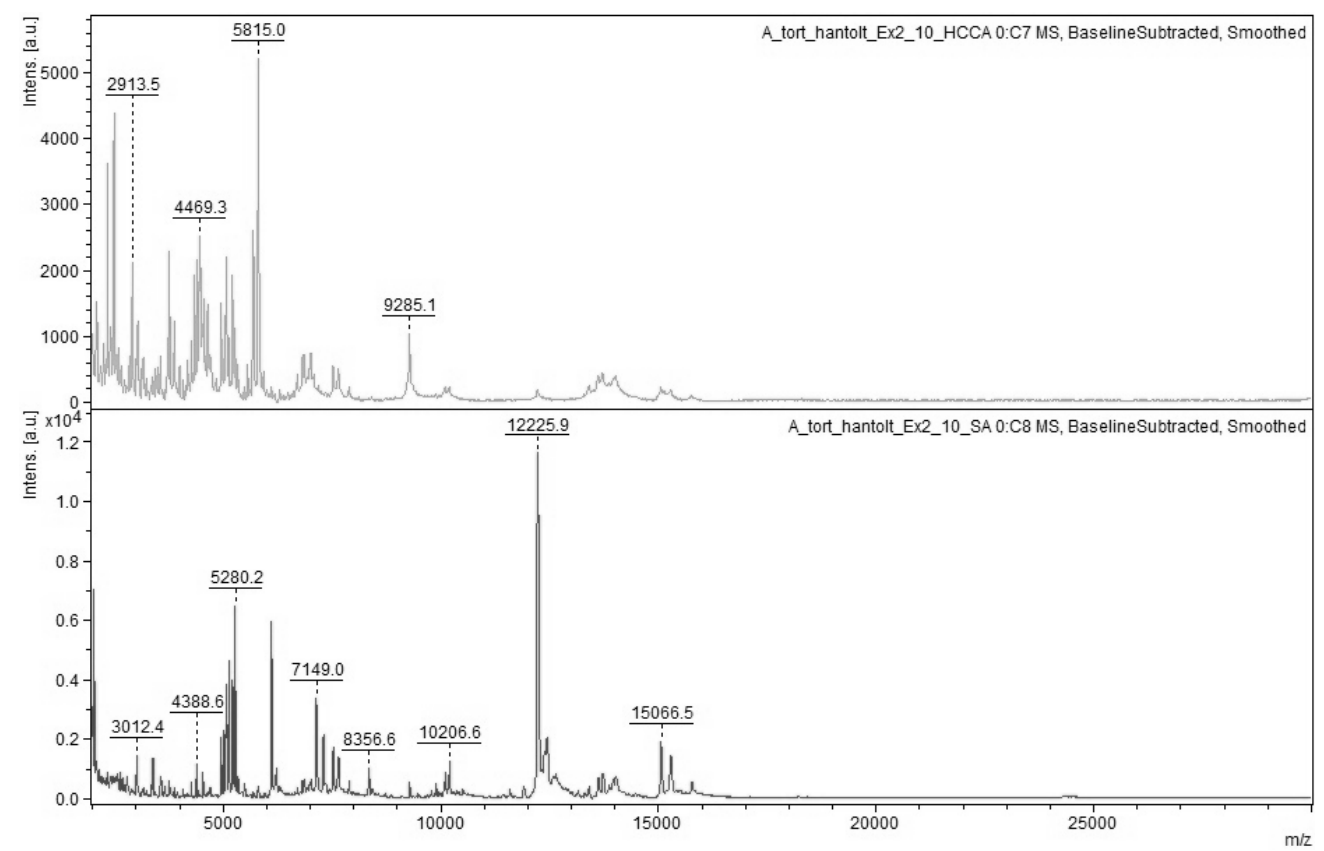

In the case of SA matrix, the spectra were more intense and noise was more thoroughly reduced. Moreover, several peaks appeared in the higher range $(10000-15000 \mathrm{~m} / \mathrm{z})$ that are essential for evaluation. During the analysis of hemp (Figure 3), the obtained spectra by SA matrix were noisier, however, also more intense than the obtained spectra by $\alpha$-HCCA matrix.
The SA matrix proved to be optimal in seed testing based on properties of spectra obtained from soybeans (Figure 4) and sunflowers (Figure 5). Using SA matrix, the intensity of the spectra more than twice as for the HCCA matrix for all three measurements (Figure 3, 4, $5)$. 


\section{CONCLUSION}

The MALDI-TOF MS technique can be used to develop a new method for analysis of seeds. Based on the obtained results, the SA matrix was more suitable for seed analysis, however, further studies are required.

\section{ACKNOWLEDGEMENTS}

The research was financed by the Higher Education Institutional Excellence Programme (204283/2018/FEKUTSTRAT) of the Ministry of Human Capacities in Hungary, within the framework of the $4^{\text {th }}$ thematic programme of the University of Debrecen.

\section{REFERENCES}

Dieckmann, R.-Helmuth, R.-Erhard, M.-Malorny, B. (2008): Rapid Classification and Identification of Salmonellae at the Species and Subspecies Levels by Whole-Cell MatrixAssisted Laser Desorption Ionization-Time of Flight Mass Spectrometry. Applied and Environmental Microbiology, 74 (24): 7767-777. DOI: 10.1128/AEM.01402-08

Gutierrez, J. A.-Dorocke, J. A.-Knierman, M. D.-Gelfanova, V.Higgs, R. E.-Koh, N. L.-Hale, J. E. (2005): Quantitative determination of peptides using matrix-assisted laser desorption/ionization time-of-flight mass spectrometry, BioTechniques, vol. 38, 13-17 pp.

Hensel, R. R.-King, R. C.-Owens, K. G. (1997): Electrospray sample preparation for improved quantitation in matrix-assisted laser desorption/ionization time-of-flight mass spectrometry, Rapid Commun. Mass Spectrom, vol. 11, 1785-1793 pp.

International Seed Testing Association (ISTA) (2017): Tetsting of seeds genetically, Rules Chapter 19, January
Lovász, Cs. (2014): A kémiai Nobel-díj és a Staphylococcus aureus. A modern tömegspektrometria szerepe a mikroorganizmusok azonosításában, Élelmiszervizsgálati közlemények. LX (4), 326$343 \mathrm{pp}$.

Mirgorodskaya, O. A.-Kozmin, Y. P.-Titov, M. I.-Korner, R.Sonksen, C. P.-Roepstorff, P. (2000): Quantitation of peptides and proteins by matrix-assisted laser desorption/ionization mass spectrometry using (18)O-labeled internal standards, Rapid Commun. Mass Spectrom, vol.14, 1226-1232 pp.

Signor, L.-Erba, E. B. (2013): Matrix-assisted Laser Desorption/Ionization Time of Flight (MALDI-TOF) Mass Spectrometric Analysis of Intact Proteins Larger than $100 \mathrm{kDa}$, Journal of Visualized Experiments, vol. 79, 1-7 pp. DOI: $10.3791 / 50635$

website: http://thermofisher.com 2016 
